\title{
HETEROGLOSIA Y DIALOGISMO EN LA POESÍA DE SHUNTARÔ TANIKAWA
}

\section{HETEROGLOSSIA AND DIALOGISM IN SHUNTARÔ TANIKAWA’S POETRY}

\author{
David TARANCO \\ Universidad Rikkyo \\ taranco@rikkyo.ac.jp
}

Resumen: La poesía, en su análisis, se ha visto por lo general excluida de elementos como el dialogismo, la heteroglosia o la polifonía, todos ellos presentados por el teórico ruso Mijail Bajtín (1895-1975) en la primera mitad del siglo XX y atribuidos desde entonces a la novela. Me propongo en este ensayo valerme precisamente de dichos recursos para analizar dos poemas de El Mickey Mouse de la noche, obra del poeta japonés Shuntarô Tanikawa ${ }^{1}$ (1931-), con el objetivo de retribuir a la poesía la capacidad dialógica que se le ha negado durante largo tiempo al circunscribirla al universo particular y cerrado del hablante lírico.

Palabras clave: Poesía; Bajtín; heteroglosia; dialogismo; Tanikawa; Japón.

Abstract: Poetry, in its analysis, has been deprived of elements such as dialogism, heteroglossia and polyphony, all of them introduced by the Russian theorist Mikhail Bakhtin (1895-1975) in the first half of the $20^{\text {th }}$ century and applied ever since to the novel. Through this essay I intend to make use of those same resources to analyse two poems from Yoru no Mickey Mouse, by the Japanese poet Shuntarô Tanikawa (1931-), in order to return poetry the dialogic ability that it has been steadily dispossessed of, being as it was constrained to the particular and closed universe of the lyrical speaker.

Key words: Poetry; Bakhtin; heteroglossia; dialogism; Tanikawa; Japan.

\footnotetext{
${ }^{1}$ A lo largo de este ensayo he optado por transcribir los nombres de los escritores japoneses con el orden habitual en español; es decir, nombre + apellido.
} 


\section{1}

\section{El prejuicio poético de Bajtín}

Parte de la teoría literaria tiende a conceder a la novela el estatus de escenario preponderante para el diálogo polifónico entre personajes dotados de estados conscientes propios y desligados del dominio ideológico del autor. Abraza así los postulados de Mijail Bajtín que, en contraposición, reduce el poema a una forma de expresión donde la ambigüedad metafórica basta para aportar a la palabra un significado doble a pesar del tono monofónico de la lírica. Así, mientras que en la novela las diferentes voces pueden ser sujetos cognitivos autónomos, héroes con ideas propias en representación de estratos sociales distintos y reflejo de diversas circunstancias históricas determinadas, la poesía impone una «dictadura de la palabra y del sentido de un estilo monológico y un tono único» (Bajtín, 1986: 286) donde no hay cabida para el dialogismo y la heteroglosia. En consecuencia, el novelista es libre de elegir entre, por un lado, enterrar su voz dentro de la multiplicidad heteroglótica inherente al género o, por otro, hacerse escuchar con una presencia firme; sin embargo, al poeta se le asigna el papel de mero ensamblador de las piezas que constituyen el lenguaje dominante del momento.

Bajtín sostiene que el autor lírico nunca aspira a subvertir el lenguaje ni tampoco pretende plasmar en sus obras las diferentes hablas de estratos sociales distintos. Es más, cuando la moda cambia y se impone un nuevo registro en las esferas dominantes, los poetas se afanan de inmediato por acuñar un lenguaje propio que satisfaga la tendencia imperante. El pensador ruso se expresa en los siguientes términos en Teoría y estética de la novela:

El poeta ve, entiende y concibe todo con los ojos de ese lenguaje, a través de sus formas internas; y cuando se expresa no siente la necesidad de recurrir a la ayuda de otro lenguaje, de un lenguaje ajeno. El lenguaje del género poético es un universo ptoloméico unitario y único, fuera del cual no existe nada y no se necesita nada. La idea de la pluralidad de los universos lingüísticos, igualmente significativos y expresivos, es orgánicamente inalcanzable para el estilo poético (1989: 103).

Dice Bajtín que el discurso poético, por consiguiente, «exige la unificación de todas las palabras; su reducción a un denominador común» (1986: 279). El autor toma la palabra como un todo y la somete a sus propósitos para enmarcar su rumbo poético dentro de una línea recta que le garantice un viaje cómodo. De este modo, el paisaje a ambos lados de la carretera reflejará únicamente sus intenciones y estas, según el teórico, no tendrán otro objetivo que apuntalar un régimen linguiístico restringido y alejado del contexto social del momento. Por consiguiente, el dialogismo entre el autor y los personajes resultará inviable ya que estos estarán supeditados a los propósitos de aquel.

En la lírica, según afirma Bajtín, solo existe «la palabra de la lengua, la palabra de nadie, la palabra cosificada que forma parte de un vocabulario poético, y esta palabra se traspone inmediatamente, del acervo de la lengua poética al contexto monológico del enunciado poético dado» (1986: 280). Es decir, el poeta asume ese lenguaje para transmitir un propósito propio y unidireccional. 
El poeta está obligado por la idea de un lenguaje único de un enunciado unitario, con carácter de monólogo, cerrado. Estas ideas son inmanentes a los géneros poéticos con los que trabaja el poeta. [...] El poeta debe entrar en posesión plena y personal de su lenguaje, debe asumir igual responsabilidad ante todos sus aspectos, someterlos directamente a sus intenciones. Cada palabra debe expresar directamente la intención del poeta; entre el poeta y su palabra no debe existir ninguna distancia (1989: 113).

En defensa de Bajtín se podría esgrimir que parte de su crítica está dirigida a la poesía neoclásica y a la poesía romántica, que leía con asiduidad y de las que era un gran conocedor. No obstante, al analizar las vanguardias, que habían irrumpido años antes en el universo poético, el teórico reprocha sin ambages a los poetas de corrientes como el simbolismo y el futurismo el empeño por crear un lenguaje «incontestable, unitario y único» en lugar de servirse de los dialectos sociales «reales» y «existentes» para impregnar a sus poemas de heteroglosia y polifonía y, así, poder establecer un dialogismo interno en la obra.

Por otro lado, Donald Wesling, al analizar el prejuicio poético de Bajtín, arguye que este era y es algo arraigado en la Rusia ortodoxa. En su opinión, el pensador ruso, deseoso de encumbrar el género novelístico y, por encima de todo, la obra de Dostoievski, pudo verse impelido a menospreciar la lírica, que por aquel entonces todavía competía con la novela por ocupar el cetro de los géneros literarios $^{2}$, a fin de conseguir su propósito. Wesling justifica a Bajtín con estas palabras: «Desde el punto de vista retórico y polémico, necesitaba hacer descender la poesía de su posición realista en la cúspide de la jerarquía de los géneros literarios a fin de elevar la prosa narrativa desde el fondo» (2003: $21)^{3}$.

Es posible, además, evocar la época y las circunstancias en que Bajtín escribió su obra, sometido siempre a la vigilancia opresora de las autoridades soviéticas. De hecho, como apunta Mara Scanlon, algunos estudiosos del teórico ruso han dejado entrever que parte de su obra podría ser una especie de criptograma y que habría que sustituir poesía por realismo socialista, «literatura que no podía atacar abiertamente en la Rusia estalinista» (2005: 4).

Sea como fuere, en su visión crítica, Bajtín sostiene que el anquilosamiento del lenguaje poético favorece el egocentrismo e impide el diálogo. Por consiguiente, incide en arrebatarle a la poesía la posibilidad de reflejar acontecimientos sociales, perspectivas históricas y particularidades cambiantes del lenguaje. Es decir, en su opinión, no es posible que agentes externos y contextos sociales plurilingües se manifiesten en los géneros poéticos. Es más, en caso de ocurrir dicho fenómeno, Bajtín desestima toda opción de polifonía y dialogismo:

[...] tras ellos no debe asomar ninguna figura lingüística socio-típica (de un posible personajenarrador), sólo existe un rostro en todas - el rostro lingüístico del autor, responsable de cada palabra como si fuera la suya propia. Sea cual sea el número y las variantes de esos hilos semánticos y acentuales, las asociaciones, las indicaciones, las alusiones, las coincidencias que provienen de cada palabra poética, satisfacen todos a un solo lenguaje, una sola perspectiva, y no a contextos sociales plurilingües (1989: 114).

\footnotetext{
${ }^{2}$ Es posible que en aquella época todavía resonaran en muchos oídos las diatribas de Samuel Taylor Coleridge (1772-1834) contra la narrativa. Coleridge consideraba que la lectura de novelas más que un pasatiempo era una pérdida de tiempo 'matatiempo' si tradujéramos literalmente el término que empleó en inglés - que no aportaba nada desde el punto de vista intelectual y que, además, conllevaba una degradación moral.

${ }^{3}$ Todos las citas extraídas de obras que aparecen en la bibliografía en una lengua que no sea el español son traducciones propias.
} 
Pero Bajtín va más allá y considera que la poesía es un instrumento totalizador del poder opresor. Al rechazar la inclusión de agentes externos y contextos sociales plurilingües, arguye, el poeta acepta que el lenguaje se convierta en «autoritario, dogmático y conservador» (1989: 104). De hecho, el teórico sugiere que los autores líricos participan de forma abierta y consciente en ese proceso. Bajtín hace hincapié en el hermetismo temático y formal de la poesía, y considera que el lenguaje poético es una suerte de herramienta concebida para un uso específico. El poeta se sirve de ella para llevar a cabo su empresa lírica sin vacilación.

El lenguaje del poeta es un lenguaje propio, en el que se encuentra, por entero y de manera inseparable, al utilizar cada forma, cada palabra, cada expresión en su sentido estricto ("sin comillas", por decirlo así); en otras palabras, como expresión pura y directa de su intención. Sean cuales sean "los sufrimientos verbales" que el poeta experimenta en el proceso de creación, el lenguaje es en la obra creada un órgano obediente, perfectamente adecuado a la intención del autor (1989: 103).

En conclusión, hemos visto hasta aquí que Bajtín niega a la poesía la posibilidad de constituir una plataforma literaria para el diálogo interno entre el autor y las palabras o entre estas mismas (dialogismo) y, del mismo modo, excluye la participación activa en el poema de contextos sociolingüísticos o personajes externos (heteroglosia). Cabe preguntarse qué ha de ocurrir entonces con el diálogo entre yo y el otro o, dicho de otro modo, entre el autor y el lector, un propósito que el propio teórico proclama de la siguiente manera: «Una obra, igual que una réplica del diálogo, está orientada hacia la respuesta de otro (de otros), hacia su respuesta comprensiva, que puede adoptar formas diversas» (1982: 265).

\section{El diálogo con el otro y algunas críticas a Bajtín}

En Problemas de la poética de Dostoievski, Bajitn afirma que el diálogo es la finalidad propia de la búsqueda del otro o, en otras palabras, ser significa comunicarse dialógicamente con el otro. «Una sola voz no concluye ni resuelve nada», asevera (1986: 355). Partiendo de esta sentencia, podemos afirmar, sin miedo a equivocarnos, que, de acuerdo con la concepción de Bajtín, la poesía no puede ser un medio de comunicación con el otro ni una búsqueda ética del ser ya que el diálogo le ha sido vedado.

En Estética de la creación verbal, el crítico vuelve a esgrimir la tiranía del autor como impedimento para el dialogismo y para el intento de realización del hombre en la búsqueda del otro.

El héroe no tiene casi nada que oponer al autor; el autor parece penetrarlo completamente dejándole en su profundidad tan solo una posibilidad potencial de independencia. El triunfo del autor sobre e1 héroe es demasiado completo, e1 héroe está absolutamente debilitado. [...] La lírica excluye todos los momentos de la expresividad espacial y de la exhaustividad del hombre, no localiza ni delimita al héroe totalmente en el mundo exterior y, por consiguiente, no ofrece la sensación de la finitud del hombre en el mundo (1982: 147 148).

De todo ello se desprende que en la poesía no hay apenas cabida para lo que Bajtín define como confesión y rendimiento de cuentas orientados hacia el otro. Ahora bien, si aceptáramos esta hipótesis, 
la lectura de un texto poético se vería cercenada y quedaría reducida a una suerte de distracción despreocupada sin el efecto de choque necesario para provocar la reflexión y la aportación del otro ${ }^{4}$. Pero ¿hemos de aceptar dicha premisa? No, en absoluto, puesto que ya hemos anunciado que el objetivo de este ensayo es precisamente rebatirla.

Algunos académicos han buscando posiciones antagonistas en otros escritos de calado. Maurice Friedman opone a Bajtín la defensa que Martin Buber hace de la lírica como escenario propicio para el diálogo: «Para Buber, [...], a diferencia de Bajtín, más que la novela, es la poesía la que atestigua que "la palabra sea hablada"» (2001: 29). En efecto, Buber afirma lo siguiente:

A diferencia de otros seres vivos, el hombre emerge frente a un mundo del que ha sido colocado a cierta distancia, y, a diferencia del resto de los seres vivos, puede entablar una y otra vez relación con él. Esta doble postura fundamental no se manifiesta en ningún otro sitio de forma más integral que en el lenguaje. El hombre — solo él — habla, porque solo él puede dirigirse al otro como otro ser situado a cierta distancia de él; pero, al dirigirse al otro, entabla relación. Este nacimiento del lenguaje también significa una nueva función de la distancia dado que incluso la primera forma de habla, como un grito o una señal, no tiene un fin en sí misma, sino que fija el mundo fuera de su ser; pero el mundo continúa, tiene continuidad. Y esta continuidad obtiene su vida de nuevo en la verdadera relación, en el habla de la palabra. El diálogo auténtico lo atestigua, y la poesía lo atestigua dado que el poema es el habla, el habla a ese Tú, dondequiera que esté (1965: 117-118).

Buber coincide con Bajtín en que la lírica, al contrario de lo que ocurre con otras artes, «no obedece a otra cosa que no sea el lenguaje» (1965: 163). Ahora bien, no le niega la función dialógica. Es más, llega a defender la idea de que la poesía no puede existir sin el diálogo auténtico entre el autor y el otro: «Si dejara de haber un diálogo auténtico, dejaría de haber poesía» (1965: 111). Si bien lo hace partiendo de posiciones ético-religiosas, Buber rebate así los argumentos de Bajtín.

En el plano exclusivo de la teoría literaria, la pérdida paulatina de interés por la lírica según avanzaba el siglo XX y la creciente posición dominante de la novela dentro de los géneros literarios hicieron que durante largo tiempo los expertos no se prodigaran en esfuerzos por refutar la postura adoptada de Bajtín con respecto a la poesía. En realidad, todavía persiste en parte de la crítica cierta tendencia a considerar que la lírica es un espacio de reclusión donde el autor expresa sus emociones a través de las palabras. Se deja a un lado, por tanto, la posibilidad de analizar la poesía más allá de su alcance como confesión individual; es decir, se concede prioridad a la lectura cercana o formalista del texto y quedan relegados del escrutinio elementos tales como el contexto histórico o los condicionamientos sociopolíticos.

Sin embargo, una vez calmadas las aguas después de la irrupción de las ideas de Bajtín en el mundo académico al conocerse más detalladamente su obra a partir de la década de 1970, poco a poco fueron surgiendo voces de diversos espectros dispuestas a sembrar dudas o impugnar sus argumentos. Citemos, por ejemplo, a Mara Scanlon. Esta sostiene que la «afirmación restrictiva» de Bajtín sobre la poesía «está a medio camino entre la ingenuidad y el atropello» (2005: 2). Scanlon se pregunta si acaso se debería aceptar que la lectura poética exige paralizar la parte del cerebro que persigue un encuentro

\footnotetext{
${ }^{4}$ Ver la teoría de Walter Benjamin sobre la distracción.
} 
ético con el otro y limitarse a disfrutar el ritmo y la metáfora. Su respuesta es no. Por otro lado, Paul de Man califica las conclusiones de Bajtín de «contradictorias» y «aberrantes» (1983: 104).

En resumen, hay críticos y pensadores que han encontrado prejuicios, valoraciones inconsistentes o contradicciones en los postulados de Bajtín. Entonces, ¿es posible afirmar que la poesía sí puede estar dotada de un carácter dialógico?

En un ensayo publicado en Bakhtin and the Classics, William W. Batstone viene a enumerar tres requisitos que la lírica debe cumplir para ser polifónica y dar cabida al dialogismo. Batstone analiza la crítica del teórico ruso y, sirviéndose de ella, demuestra que algunas de las composiciones del poeta latino Catulo son del todo polifónicas y dialógicas. Los tres principios que, en su opinión, deben cumplirse para ello son los siguientes:

1) el yo debe ser polifónico e interpersonal; es decir, el autor ha de ser capaz de transferir al poema las diferentes voces que dialogan en el interior de su mente de forma que cada una mantenga su independencia;

2) el yo debe ser una especie de sujeto elusivo o guadianesco que juegue al escondite con las otras voces del poema apareciendo y desapareciendo;

3) el yo elusivo debe dejar paso a un lector dotado de capacidad de comprensión y creación, es decir, autoría o, dicho de otro modo, capacidad de completar el poema.

Después de haber precisado la postura de Bajtín y una vez presentadas algunas voces que la refutan o contradicen, el respaldo teórico de Batstone y la misma definición que hace el pensador ruso de la heteroglosia y el dialogismo deberían servirnos para encontrar en la obra del poeta japonés Shuntarô Tanikwawa dichos elementos. En primer lugar, descubramos a grandes rasgos quién es Tanikawa.

\section{Shuntarô Tanikawa y el dialogismo poético}

No es exagerado decir que estamos ante el máximo representante de la poesía japonesa contemporánea. Activo desde los años de la posguerra, Shuntarô Tanikawa es el poeta más leído y reconocido en Japón. Su obra corona el proceso de renovación de la lírica nacional, iniciado tras el contacto con la poesía occidental durante la era Meiji (1868-1912).

Desde la publicación en 1882 de Shintaishish $\hat{o}^{5}$, la primera gran antología de traducciones líricas, hasta la irrupción editorial de Tanikawa en 1952, poetas como Tôson Shimazaki, Tôkoku Kitamura, Sakutarô Hagiwara, Tarô Tominaga, Chûya Nakahara, Shigeji Tsuboi o Jun Okamoto y autores/traductores como Ôgai Mori, Bin Ueda, Kafu Nagai y Daigaku Horiguchi fueron introduciendo

\footnotetext{
${ }^{5}$ Este libro, cuyo título significa literalmente Antología de poesía de estilo nuevo, incluye traducciones de autores como Tennyson, Gray, Campbell, Longfellow o Shakespeare, así como algunos poemas originales de ese estilo innovador que preconizaban los autores/traductores.
} 
en Japón el romanticismo, el modernismo, el simbolismo, el dadaísmo y otras corrientes poéticas. Después de imitaciones, tanteos y experimentos varios, puede decirse que Tanikawa emergió como el primer poeta japonés capaz de asimilar las corrientes vanguardistas de Occidente y fundirlas de forma natural con la esencia lírica tradicional, la herencia cultural y el acervo popular de Japón en una poesía personal y moderna.

Tanikawa se distingue en su temática por retratar episodios cotidianos en los que con frecuencia plantea cuestiones vitales en una búsqueda permanente de la armonía universal, entendida esta como la confraternización humana y la sana convivencia con el cosmos (= la vida). En cuanto a la forma, emplea por igual el verso libre y la prosa poética. Lo hace con un lenguaje sencillo que, en ocasiones, libera de normas sintácticas y semánticas eliminando las ramificaciones connotativas de la palabra y tratando de borrar incluso la significación denotativa de esta. El poeta japonés habla así sobre el lenguaje lírico:

Dicen que una palabra como 'amor' alude ahora a una realidad que trasciende la unión física entre un hombre y una mujer. Yo no lo veo así. El significado que expresan las palabras dentro de la poesía no responde a la exactitud que se le atribuye por regla general. Más bien, creo que responde a la violencia que hay en su interpelación. El lenguaje poético, a diferencia del lenguaje convencional, no está hecho para representar las cosas. (2006b: 29-30)

Además de romper el canon clásico japonés de formas como el haiku, donde existen unas connotaciones inamovibles que comparten el autor y los lectores ${ }^{6}$, Tanikawa se distancia de otros autores contemporáneos que se sirven del lenguaje como herramienta dada. En este aspecto, su proceder parece refrendar el consejo de Richard Rorty a los poetas en la búsqueda de un lenguaje nuevo ${ }^{7}$.

Hemos mencionado anteriormente que uno de los hechos más remarcables en la obra de Tanikawa es el intento de desmantelar el armazón de significados que arrastra cada significante. En gran parte de su obra, una de las intenciones del autor es «destruir el lenguaje», tanto en el nivel sintáctico como en el valor semántico de las palabras. Así, va creando una voz propia. Un elemento al que recurre con frecuencia para ello son las onomatopeyas. En opinión de Tanikawa, las onomatopeyas constituyen una figura retórica que promueve la libertad creativa del autor y del lector, ya que nos acercan al estado primitivo del lenguaje antes de que este adquiriera significado: «El lenguaje humano evolucionó desde los gritos de los animales hasta ir articulando sonidos que fueron adquiriendo significado» (2010: 38-39).

En la búsqueda de ese estado primitivo del lenguaje y en su intento de creación de un universo de armonía para toda la humanidad, Tanikawa se acerca a Graham Pechey, que, al hablar de Bajtín, fantasea con la posibilidad de crear una especie de lenguaje poético redentor: «Al imaginar una condición en la que una persona fuera todos, el lenguaje pseudoadamita al que aspira la poesía exige

\footnotetext{
${ }^{6}$ El comparatista japonés Kôji Kawamoto apunta que tan solo en la lírica tradicional de Japón el lenguaje puede tratarse como signos matemáticos que contienen una información exacta sin dejar espacio a la respuesta del lector.

${ }^{7}$ En un pasaje de Contingencia, ironía y solidaridad, Rorty viene a decir que, a diferencia del artesano, que sabe con qué materiales trabaja, el poeta debe labrarse un lenguaje nuevo en su actividad creadora.
} 
de nosotros cierta visión binocular, una perspectiva 'más allá del bien y el mal' que sea capaz de unir todos los tiempos tanto en su promesa como en su misterio» (2007: 111).

Estos atributos que distinguen a Tanikawa como poeta nos hacen vislumbrar la posibilidad de encontrar en sus composiciones líricas el dialogismo heteroglótico y la interpelación al otro.

Pasemos entonces a analizar el primero de los dos poemas que he seleccionado para este trabajo. Pertenece al poemario El Mickey Mouse de la noche ${ }^{8}$, publicado en 2003 y todavía inédito en español. Se titula El pato Donald de la mañana y se abre con esta estrofa:

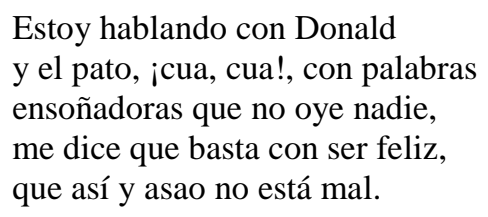

¿Cómo hemos de interpretar ese «icua, cua!»? Tanikawa dice que nadie oye las palabras del pato, pero ¿acaso no está incitando al lector a escuchar con atención? El autor interpreta el graznido como una invitación a buscar la felicidad. Pero, al mismo tiempo, ese no entendimiento deja abierta la puerta a múltiples interpretaciones. Muy posiblemente cada uno de nosotros sería capaz de construir una historia detrás del alarido de Donald. El poema continúa así:

Flotando sutilmente sobre el agua me dice:
«QQue sepas que yo también soy un dios!
¿Ves lo que hay debajo de mi plumaje blanco?
Ahí, más abajo, están mis entrañas rosáceas,
pero ¿y la vida?, ¿ves dónde está?».

En esta estrofa observamos una interpelación directa del personaje del poema a su autor y, por extensión, podríamos afirmar, al lector. Tanikawa desaparece de forma momentánea y deja que el pato Donald sea el protagonista del discurso lírico. Se cumple así el segundo de los requisitos de Batstone. Por otro lado, dice Bajtín que la palabra del discurso polifónico «expresa a un tiempo dos intenciones diferentes: la intención directa del héroe hablante y la refractada del autor», dos voces que están «relacionadas dialogísticamente entre sí» (1989: 141-142). ¿No estamos asistiendo aquí a un diálogo entre la voz segura y preceptora de Donald y la voz dubitativa e inquisitiva de Tanikawa? Yo pienso que sí. La transformación en héroe poético de Donald, un pato de carácter optimista y resuelto por naturaleza, puede darnos una pista sobre las intenciones del autor, que parece estar trasladando a la composición poética las voces dialogantes de su mente. Se contrapone la seguridad y el desparpajo del personaje de Disney a la vacilación espiritual del poeta o, tal vez, este juego de voces no sea más que el reflejo de la propia duplicidad de emociones de Tanikawa. Este vuelve a surgir en la tercera estrofa con una referencia en el verso de cierre a su estado físico y anímico.

Amanece y Donald emprende un viaje a alguna parte:

¿se ha ido chapoteando, me pregunto, o

\footnotetext{
${ }^{8}$ Las dos composiciones extraídas de este poemario para su análisis en el presente ensayo son traducciones propias de la versión original en japonés.
} 
ha batido las alas y ha partido así sin más?

Solo quedan de él las ondas que se propagan

mientras mi cuerpo y mi alma se parecen ahora al agua.

Donald se esfuma y el autor se queda expuesto a su soledad con la obligación de reflexionar sobre el episodio que acaba de presenciar. Pero no solo él ha de mirarse las entrañas, sino también el lector, que se ve conminado a realizar la misma introspección; es decir, retomando las palabras antes citadas de Buber, el poema tiene continuidad en el otro, del que se espera una reacción. La cuarta y última estrofa nos lo deja aún más claro.

\footnotetext{
¿He de dejarme arrastrar o quedarme estancado? ¿Debería congelarme o elevarme convertido en vapor? Como este cuerpo no me permite elegir siquiera eso, todo cuanto quiero es colmar en silencio esta vasija que la gente y las plantas circundan.
}

Cabe preguntarse si todas estas preguntas acaso no están dirigidas al lector, es decir, al otro. Este debería después asumir su función, pues «el dialogismo entre el lector y el texto [...] da como resultado una responsabilidad ética para el lector que responde al poema» (2007: 9). Y gracias a dicha respuesta, de cuya existencia no tenemos por qué dudar, el poema se mantiene vivo en el tiempo. Como apunta Friedman parafraseando a Buber: «La palabra escrita [...] reclama el diálogo con el otro, el Tú al que se habla. Al responder a la interpelación de la obra literaria, el lector e intérprete eleva de nuevo las palabras escritas a "una esfera de palabra viva" y, como resultado, la obra literaria "siempre revive"» (2001: 30).

¿Acaso no aspiraba Bajtín a que toda obra literaria perdurara en el tiempo y fuera reinterpretada de acuerdo con el contexto sociopolítico de la época? Sin duda alguna, las respuestas a las preguntas que plantea el poema serían resultas de manera diferente en función de las circunstancias del momento. De este modo, Tanikawa consigue que su obra sea un instrumento útil en manos del lector, que puede darle forma a su antojo y adecuarlo a sus inquietudes y necesidades en la vida cotidiana.

Por tanto, en El pato Donald de la mañana se constata la presencia de un dialogismo interno en el poema y se plantea la posibilidad de que exista una comunicación dialógica entre el autor y el lector. Utilizando los mismos elementos de Bajtín lo hemos podido demostrar.

Analicemos ahora el segundo poema. Se titula Astroboy ha cumplido 103 años. Su protagonista es el personaje de Astroboy ${ }^{9}$, una serie de televisión japonesa que marcó un antes y un después en el mundo de los dibujos animados en la década de 1960. También supuso el primer éxito internacional del anime japonés. La obra está basada en el manga homónimo de Osamu Tezuka. Comienza así:

\footnotetext{
Astroboy, que ya ha cumplido 103 años pero conserva el rostro como el día en que nació, contempla el atardecer a la orilla de un lago en medio de la nada, mientras unos cuervos en bandada regresan a sus nidos.

Cuántas veces no se lo habrá preguntado:

«Con un conocimiento superior a la media de los mortales,
}

\footnotetext{
${ }^{9}$ En japonés, la serie se llama 鉄腕アトム (Tetsuwan Atom o, literalmente, Atom, el brazo de hierro).
} 
con una bondad que no tiene nada que envidiar a la de Tora $\operatorname{san}^{10}$, ¿acaso tengo yo algo que pueda llamarse alma?».

Como ocurría en el poema anterior, vemos en la primera estrofa que el héroe aparece localizado en medio de la naturaleza y sin nadie que lo acompañe. En los versos siguientes, ante la ausencia manifiesta del poeta en la escena descrita, es decir, sin interlocutor directo al que dirigirse, el robot humanoide se pregunta a sí mismo cómo es posible que él no tenga alma a pesar del conocimiento intelectual y el corazón magnánimo con que fue dotado en su concepción. Entonces, Astroboy rememora un encuentro pasado con Peter Pan y deja que sea el autor quien lo cuente en el tercer cuarteto.

Un día, cuando se encontró con Peter Pan, este le dijo:

- ¡He oído que tú no tienes pito!

- ¿Se parece eso al alma?

Y recuerda que, al oír su respuesta, Peter se echó a reír.

La inclusión del personaje de Peter Pan permite a Tanikawa introducir un lenguaje que responde a un registro y a un contexto que difieren del resto del poema. La forma irónica en que se dirige al robot el niño del país de Nunca Jamás y el empleo por parte de este de la palabra «pito» aportan a la composición una heteroglosia marcada. Esta se ve reforzada por la respuesta ingenua de Astroboy en la forma de pregunta: «¿Se parece eso al alma?».

Algunos teóricos han destacado el papel activo de la ironía como elemento desencadenante de la polifonía heteroglótica. En Constantinos Cavafis y Jaime Gil de Biedma: Dos poetas, una concepción vital y estética, Styliani Voutsa afirma lo siguiente: «La polifonía está in situ en cada ironía porque toda enunciación irónica contiene dos puntos de vista diferentes, dos maneras distintas de ver el mundo: estas dos perspectivas pueden expresarse en una frase o pueden ocupar una novela entera» (Voutsa, 2012: 335).

La última acotación de esta cita es una refutación directa de la teoría de Bajtín expuesta en la primera parte de este ensayo. En su libro, Voutsa también defiende la posibilidad de la polifonía y el dialogismo en la poesía.

Por otro lado, en el diálogo entre Astroboy y Peter Pan podemos percibir una búsqueda de reconocimiento y reafirmación por parte del robot humanoide. Este espera que el niño establezca una diferencia clara entre los seres fantásticos de Nunca Jamás y Astroboy, pero la réplica resulta equívoca. $¿$ No debemos encontrar en el propio miedo de Peter Pan a crecer el origen de su respuesta? Ninguno de los dos personajes en escena puede aceptar la situación porque, como dice el propio Bajtín al hablar de los héroes narrativos, «quedaría en una posición débil y pasiva [...]. Su orgullo no puede soportar esto (1986: 356-357). Peter Pan elude su realidad con una risa sarcástica y se va. Por lo que respecta a

\footnotetext{
${ }^{10}$ Personaje protagonista de la serie de películas Otoko wa tsurai yo, que podría traducirse como Qué duro es ser hombre. Tora san (el señor Tora) es un vendedor afable y generoso que vaga de ciudad en ciudad soñando con realizar grandes hazañas y conquistar el corazón de una mujer, pero que vuelve siempre a casa cariacontecido por su poca fortuna.
} 
Astroboy, justo en ese momento llega a sus oídos el eco de una canción ${ }^{11}$ que lo describe como un ser «tierno de corazón», «justo», «protector de la humanidad»y «amigo de todos». Las reacciones de los dos protagonistas resultan antagónicas y, en consecuencia, nos acercan más si cabe a la heteroglosia de Bajtín. El poema continúa así:

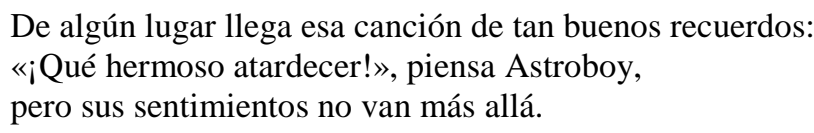

Nuestro héroe, apaciguado por el enunciado lisonjero de la canción, ya no necesita pensar en nada más. En la última estrofa, Astroboy, convencido de su humanidad, llega a la conclusión de que tuvo que haber un error cuando lo crearon porque, en el fondo, él sí tiene corazón.

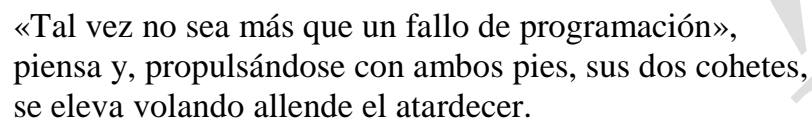

El robot humanoide se retira y deja al lector pensativo. El público japonés, que evoca de inmediato la letra de la canción, se ve apremiado a juzgar la humanidad de Astroboy. ¿Acaso no es el robot más humano que todos nosotros en su comportamiento recto y filántropo? De nuevo Tanikawa parece estar conversando con el otro a través de sus versos.

\section{Conclusión}

En la obra de Tanikawa, gracias a un lenguaje sencillo y desprovisto de metáforas, la voz totalitaria del poeta que criticaba Bajtín se difumina entre el lenguaje lírico. No es necesario que el grito poético imponga su «dictadura» y se haga escuchar. De este modo, el autor puede bajarse del «vehículo flotante» de la metáfora al que aludía Derrida en La retirada de la metáfora, reducir el lenguaje a su naturaleza virginal —el propósito expreso de Tanikawa- y dejar que sea el lector quien le otorgue un significado acorde a su estado personal y al contexto social presente. Es un ideal poético que, como defendía Buber, permite el dialogismo con el otro y deja la interpretación en manos de la metafísica del público.

En cuanto a la polifonía heteroglótica que Bajtín también le niega a la poesía, creo que ha quedado demostrada su existencia por medio del análisis de las diferentes voces presentes en los dos poemas: por un lado, la interpelación del pato Donald al autor, en el primer poema, y, por otro, la conversación cargada de ironía y constricción entre Astroboy y Peter Pan en la segunda composición.

\footnotetext{
${ }^{11}$ Shuntaro Tanikawa escribió la letra del tema principal de la serie Astroboy. En la canción se ponderan las cualidades humanas del robot.
} 
Heteroglosia y dialogismo en la poesía de Shuntarô Tanikawa

\section{Referencias bibliográficas}

BaJTín, M. (1982): Estética de la creación verbal. Trad. Tatiana Bubnova. México, Siglo XXI, 10. ${ }^{\text {a }}$ ed., 1999.

(1986): Problemas de la poética de Dostoievski. Trad. Tatiana Bubnova. México, Fondo de Cultura Económica, 1. ${ }^{\text {a }}$ reimpresión, 1988.

(1989): Teoría y estética de la novela. Trad. Helena S. Kriúkova y Vicente Cazcarra. Madrid, Taurus.

Batstone, W. W. (2002): «Catullus and Bakhtin: The Problems of a Dialogic Lyric», en R. Bracht BrANHAM, ed., Bakhtin and the Classics. Evanston, Northwestern University Press, pp. 99-136. Benjamin, A., ed. (2005): Walter Benjamin and Art. Nueva York, Continuum.

Buber, M. (1965): The Knowledge of Man. Nueva York, Harper \& Row.

De MAN, P. (1983): «Dialogue and Dialogism», Poetics Today, 4/1, pp. 99-107.

DERRIDA, J. (1989): La deconstrucción en las fronteras de la filosofía. Trad. Patricio Peñalver Gómez. Barcelona, Paidós.

FRIEDMAN, M. S. (2001): «Martin Buber and Mikhail Bakhtin: The Dialogue of Voices and the Word That Is Spoken», Religion \& Literature, 33/3 (Autumn), pp. 25-36.

(2002): Martin Buber, The Life of Dialogue. Abingdon, Routledge.

KAWAMOTO, K. (1991): Nihon shiika no dentô (日本詩歌の伝統). Tokio, Iwanami. (Trad. al inglés en 2010 como The Poetics of Japanese Verse - Imagery, Structure, Meter. Tokio, University of Tokyo Press).

PeChey, G. (2007): Mikhail Bakhtin, The Word in the World. Abingdon, Routledge.

RoRTY, R. (1989): Contingency, Irony and Solidarity. Cambridge. Cambridge University Press.

SCANLON, M. (2007): «Ethics and the Lyric: Form, Dialogue and Answerability», College Literature, 34/1 (Winter), pp. 1-22.

TANIKAWA, S. (2003): Yoru no Mickey Mouse (夜のミッキー・マウス). Tokio, Shinchôsha.

— (2006a): Shi wo kaku. Naze watashi wa shi wo tsukuru ka (詩を書く。なぜ私は詩をつくる か). Tokio, Shichôsha.

(2006b): Shi wo kangaeru. Kotoba ga umareru genba (詩を考える。言葉が生まれる現場). Tokio, Shichôsha.

TANIKAWA, S. - WAGÔ, R. (2010): Nihongo no hanashi (にほんごの話). Tokio, Seidosha.

Voutsa, S. (2012): Constantinos Cavafis y Jaime Gil de Biedma: Dos poetas, una concepción vital y estética. Salamanca, Universidad de Salamanca.

WesLing, D. (2003): Bakhtin and the Social Mooring of Poetry. Londres, Associated University Press. 